Article

\title{
Experimental Analysis of Soil and Mandarin Orange Plants Treated with Heavy Metals Found in Oilfield-Produced Wastewater
}

\author{
Ailin Zhang ${ }^{1}$, Veronica Cortes ${ }^{2}$, Bradley Phelps ${ }^{2}$, Hal van Ryswyk ${ }^{1}$ and Tanja Srebotnjak ${ }^{3, *}$ \\ 1 Chemistry Department, Harvey Mudd College, 301 Platt Blvd, Claremont, CA 91711, USA; \\ azhang@g.hmc.edu (A.Z.); vanryswyk@g.hmc.edu (H.v.R.) \\ 2 Engineering Department, Harvey Mudd College, 301 Platt Blvd, Claremont, CA 91711, USA; \\ vcortes@g.hmc.edu (V.C.); bjphelps@g.hmc.edu (B.P.) \\ 3 Hixon Center for Sustainable Environmental Design, Harvey Mudd College, 301 Platt Blvd, Claremont, \\ CA 91711, USA \\ * Correspondence: tsrebotnjak@g.hmc.edu; Tel.: +1-909-621-8751
}

Received: 4 April 2018; Accepted: 6 May 2018; Published: 9 May 2018

\begin{abstract}
Despite a declining trend, California remains a significant oil-producing state. For every barrel of crude oil, an average of 15 barrels of oilfield produced water (OPW) is generated, some of which is used to boost freshwater sources for crop irrigation in the agriculturally important Central Valley. OPW is known to contain salts, metals, hydrocarbons, alkylphenols, naturally radioactive materials, biocides, and other compounds from drilling and production processes. Less is known about the potential uptake and accumulation of these compounds in crops and soil irrigated with OPW. In this study, 23 potted mandarin orange plants were irrigated two to three times weekly (depending on season) with water containing three different concentrations of the known OPW heavy metals barium, chromium, lead, and silver. Seven sets of samples of soil and leaves and 11 fruits were collected and processed using microwave-assisted digestion (EPA Method 3051A). Processed samples were analyzed using inductively coupled plasma-optical emission spectroscopy (ICP-OES). Analysis of variance (ANOVA) and covariance (ANCOVA) coupled with Tukey's honest significant difference test were used to examine the effects of metal concentrations in the irrigation water and number of watering days, respectively, on the metal concentrations in the soil, leaf, and fruit samples. Accumulation of barium in soil and leaves was strongly positively associated with sample and number of watering days, increasing nearly 2000-fold. Lead also showed an upward trend, increasing up to 560-fold over the baseline level. Total chromium showed an increase in the soil that tapered off, but less consistent results in the leaves and fruit. The silver results were more volatile, but also indicated at least some level of accumulation in the tested media. The smallest absolute accumulation was observed for chromium. Concentrations in the fruit were highest in the peel, followed by pith and juice. Accumulation of all heavy metals was generally highest in the soil and plants that received the highest irrigation water concentration. Considering the potential for adverse human health effects associated with ingesting soluble barium contained in food and drinking water, and to a lesser extent chromium and lead, the study signals that it is important to conduct further research into the accessibility and bioavailability of the tested heavy metals in the soil and whether they pose risks to consumers.
\end{abstract}

Keywords: oilfield produced water; wastewater; heavy metals; irrigation; bioaccumulation; soil health; California 


\section{Introduction}

California is still the third-largest oil-producing state in the United States [1]. During the oil production process, substantial volumes of oilfield produced water (OPW, also referred to as oilfield brine, connate water, or formation water) are typically generated, especially as the well and oilfield matures. The origins of the briny water include flow from above, within, and below the targeted hydrocarbon zone as well as flow from injected fluids and additives employed during the production process [2]. OPW is the largest waste stream by volume in the exploration and extraction of oil, and over the lifespan of an oilfield the total volume of produced water can exceed tenfold the volume of hydrocarbons produced [3]. In 2012, for example, California generated an estimated 21 billion barrels of OPW, i.e., approximately 15 barrels of OPW for every barrel of oil [4].

In general, OPW is high in salts and dissolved solids and may also contain metals, alkylphenols, trace elements, hydrocarbons, polycyclic aromatic hydrocarbons (PAHs), volatile organic compounds (VOCs), benzene, toluene, ethylbenzene, and xylenes (collectively known as BTEX), naturally occurring radioactive materials (NORMs), biocides, and other compounds used during the production process [3]. Concentrations of total dissolved solids (TDS) in OPW range from a few thousand $\mathrm{mg} / \mathrm{L}$ to several hundred thousand $\mathrm{mg} / \mathrm{L}$ [2]. In the Western U.S., including several California oilfields, measured concentrations range from $1000 \mathrm{mg} / \mathrm{L}$ to $400,000 \mathrm{mg} / \mathrm{L}$ [5]. A case study analyzing the composition of OPW from 630 producing oil and gas wells in California that were stimulated through hydraulic fracturing found that the average concentration of $\mathrm{Cr}(\mathrm{VI})$ in the $\mathrm{OPW}$ was $8.5 \mu \mathrm{g} / \mathrm{L}$, while the average concentrations of Sb was $1100 \mu \mathrm{g} / \mathrm{L}$, As $1100 \mu \mathrm{g} / \mathrm{L}, \mathrm{Cd} 40 \mu \mathrm{g} / \mathrm{L}, \mathrm{Pb} 420 \mu \mathrm{g} / \mathrm{L}$, Se $1900 \mu \mathrm{g} / \mathrm{L}$, and Zn $420 \mu \mathrm{g} / \mathrm{L}$ [4]. Many of the elements and compounds used in oil well drilling and production can have varying adverse health effects on the gastrointestinal tract, the nervous system, and the reproductive system when ingested.

Although the most common method for managing OPW in California is deep-well injection and disposal in evaporation-percolation pits, accounting for $60 \%$ and $18 \%$ of total OPW disposal, respectively, a small fraction of California's OPW is applied to land surfaces [6]. The Clean Water Act stipulates effluent guidelines for on-shore oil and gas extraction facilities that prohibit the discharge of pollutants into surface waters, except for wastewater that is of good enough quality for use in agricultural and wildlife propagation for onshore facilities located in the continental United States and west of the 98th meridian. This creates the possibility for reusing OPW in agricultural crop irrigation, as is the case in California's Central Valley.

Although OPW has been reused in surface applications for more than 20 years, it gained wider prominence and interest during the exceptional drought that gripped California between 2011-2016 as a means to supplement heavily constrained agricultural freshwater supplies [7,8]. However, the question of whether it can be done safely for consumers, agricultural workers, and communities living near OPW application sites has not been sufficiently answered to date [9]. Among the concerns voiced by public health and environmental groups is whether toxic OPW compounds, such as heavy metals, may become bioavailable and accumulate in parts of the crops intended for human consumption [9]. Concerns about long-term soil health and productivity have also been raised [9]. There is a substantial body of literature, involving field and laboratory studies, regarding the origins, environmental and health effects, and remediation of soil contamination with heavy metals, including $\mathrm{Ba}, \mathrm{Cd}, \mathrm{Pb}$, and As [10-16]. Studies by Fliessbach et al. (1994) and Khan et al. (2000) show the negative effects on soil productivity resulting from heavy metal contamination [17-19]. Furthermore, Pontoni et al. (2016a,b) studied the accumulation, mobility, and fate in soil of trace amounts of $\mathrm{Ni}, \mathrm{Cd}, \mathrm{Cu}$, and $\mathrm{Zn}$ and found, inter alia, that the metals accumulate mostly in the top soil layer and that their accumulation pattern depends on the mobility of colloids in the case of $\mathrm{Ni}, \mathrm{Cd}$, and $\mathrm{Cu}$, while for $\mathrm{Zn}$ the wastewater content of dissolved organic matter and its salinity played greater roles [20,21].

While soil accumulation has been widely documented, Toze (2009) found evidence that the seeds and leaves of flax, cotton, and rice store only a small percentage of the heavy metals compared to soils [22]. However, even small concentrations may pose health risks if the crop is consumed frequently, 
such as rice, or in larger amounts over a short period of time, such as seasonal crops like mandarin oranges. A study in Tongzhou District, Beijing, China, in 2007 examined wastewater-irrigated soils used to grow radish, maize, spinach, green cabbage, cauliflower, turnip, and lettuce [23]. It found significant correlations between heavy metal concentration in soils and the edible parts of plants for $\mathrm{Cd}, \mathrm{Cu}, \mathrm{Pb}$, and $\mathrm{Zn}$. In particular, the concentrations of $\mathrm{Cd}, \mathrm{Cr}$, and $\mathrm{Ni}$ exceeded regulatory limits set by the State Environmental Protection Administration [21]. Similar issues are known to arise in the proximity of metal ore mines. For example, the soil and corn, jujube, perilla, red pepper, soybean, and spring onions grown near a copper-tungsten mine in South East Korea were found to have elevated concentrations of $\mathrm{Cu}, \mathrm{Zn}, \mathrm{Cd}$, and $\mathrm{Pb}$ [24]. Concentrations varied with crop species and higher concentrations were found in the leafy material of the crops compared with the fruit and seeds. The study also determined that the most dominant factor affecting metal uptake in plants was the metal content in the surface soil, which may be problematic in the long-term application of OPW wastewater [24]. Owsianiak et al. $(2013,2015)$ cautioned against estimating toxicity impacts from measured total soluble metal concentrations alone. They find that the bioaccumulation patterns and resulting eco-toxicity depend on the metals' accessibility and bioavailability, which are influenced by environmental chemistry factors such as soil $\mathrm{pH}$, organic matter content, and the pore water concentration of other metals $[25,26]$.

While the existing literature demonstrates the potential for plant uptake of metals through soil and irrigation water, it is of specific interest to look into the potential soil and crop impacts of OPW reuse in agriculture in California's Central Valley. As of now, water quality monitoring involving OPW is limited and not federally regulated [5]. In response to concerns raised by environmental and public health organizations, the Central Valley Regional Water Board initiated a Food Safety Expert Panel tasked with examining the available evidence and conducting studies for testing the risk involved in OPW reuse in the region's agricultural operations, primarily citrus, almond, pistachio, and table grape farming and to a lesser extent garlic, carrot, and tomato plantings [9]. The panel commissioned sampling campaigns in the spring and summer of 2017 for table grapes, citrus, almonds, garlic, and pistachios and tested the edible fruit for over 100 organic, inorganic, and metal analytes. A total of 16 compound or elements were detected, among them the metals $\mathrm{Ba}, \mathrm{Cu}, \mathrm{Mo}, \mathrm{Ni}, \mathrm{Sr}$, and $\mathrm{Zn}$, although at mostly low concentrations [27].

The present study complements the work of the Food Expert Panel with an observational study of the uptake of $\mathrm{Ba}, \mathrm{Cr}, \mathrm{Pb}$, and $\mathrm{Ag}$ in the soil, leaves, and fruit of mandarin orange plants as a result of the controlled application of heavy metal tainted irrigation water. The goal of the study is to identify if and to what extent the tested heavy metals accumulate in the soil, leaves, and/or fruit in response to sampling time and the concentration of heavy metals used in the irrigation water.

\section{Materials and Methods}

A total of 23 mandarin orange trees, representing six varieties found in California's Central Valley and residential gardens, were purchased in 5 gal. pots from the same local nursery in late spring 2017. The plants were semi-randomly assigned to receiving irrigation water with three different concentration levels of $\mathrm{Ba}, \mathrm{Cr}, \mathrm{Pb}$, and $\mathrm{Ag}$ ions, ranging from $25 \mathrm{mg} / \mathrm{L}-3000 \mathrm{mg} / \mathrm{L}$ for $\mathrm{Ba}, 0.01 \mathrm{mg} / \mathrm{L}-0.10 \mathrm{mg} / \mathrm{L}$ for $\mathrm{Cr}, 5.0 \mathrm{mg} / \mathrm{L}-30 \mathrm{mg} / \mathrm{L}$ for $\mathrm{Pb}$, and $1.0 \mathrm{mg} / \mathrm{L}-15 \mathrm{mg} / \mathrm{L}$ for $\mathrm{Ag}$ (see Table 1 for details). These ranges reflect measurements reported in the OPW literature [2,28]. The tested metals are known for their risks to human health and soil productivity. Nitrate salts were used due to their high solubilities and the general lack of adverse effects on plant growth at the levels employed in this study. The high concentration level was selected to test for substantial plant effects such as growth decline and mortality. The procedure was semi-random, because fruit-bearing plants were allocated such that each concentration level had at least two plants with fruits. 
Table 1. Range of concentrations of heavy metal ions observed in produced water for the tested heavy metals $\mathrm{Ba}, \mathrm{Cr}, \mathrm{Pb}$, and $\mathrm{Ag}$.

\begin{tabular}{ccccc}
\hline Metal Salt & $\begin{array}{c}\text { Low } \\
\text { Concentration of } \\
\text { Metal Ion }(\mathbf{m g} / \mathrm{L})\end{array}$ & $\begin{array}{c}\text { Medium } \\
\text { Concentration of } \\
\text { Metal Ion }(\mathbf{m g} / \mathrm{L})\end{array}$ & $\begin{array}{c}\text { High } \\
\text { Concentration of } \\
\text { Metal Ion }(\mathbf{m g} / \mathrm{L})\end{array}$ & $\begin{array}{c}\text { Concentration Ranges of } \\
\text { Metal Ions Reported in } \\
\text { Literature }(\mathbf{m g} / \mathrm{L})\end{array}$ \\
\hline Barium nitrate & 25.0 & 1500 & 3000 & $9.65-1740$ \\
\hline Chromium(III) nitrate & 0.01 & 0.03 & 0.10 & ND-0.03 \\
\hline Lead nitrate & 5.0 & 10.0 & 30.0 & $<0.2-10.2$ \\
\hline Silver nitrate & 1.0 & 7.0 & 15.0 & $0.047-7.0$ \\
\hline Number of plants & $7^{*}$ & 8 & 8 & \\
\hline
\end{tabular}

Note: ND refers to not detected, LOD refers to the Limit of Detection. The low concentration levels were well above the LOD of the inductively coupled plasma-optical emission spectroscopy (ICP-OES) instrument. * A temporary, region-wide shortage in citrus plants meant that only 23 instead of 24 plants could be purchased within a reasonable timeframe.

Prior to commencing irrigation (or treatment) with the three levels of heavy metal concentrations, the baseline (or control) concentrations in the soil and leaves were determined. Plants were then watered twice (cold season) or three times (hot season) weekly. The watering frequency was based on recommendations received from the nursery regarding watering amounts and frequencies supporting healthy plant growth. During August and mid-December through mid-January the plants were watered with freshwater due to breaks in the academic calendar. Samples of soil and leaves were taken every two weeks during the active experimentation period. The fruit was harvested for analysis at the end of the experiment in March 2018.

Watering solutions were prepared on the days of irrigation. Each plant received 0.5 gal. $(1.89 \mathrm{~L})$ of heavy metal solution at every watering for a total of 22.5 gal. received at $w=43$, i.e., the day that the final soil and leaf samples were collected. The soil and leaf samples were then processed by microwave-assisted digestion using U.S. Environmental Protection Agency (EPA) Method 3051A. Method blanks were run for each analysis. Specifically, in a typical procedure, $0.300 \mathrm{~g}$ of soil or leaf were dried at $60{ }^{\circ} \mathrm{C}$ for 3 days, digested with $12 \mathrm{~mL}$ of $\left(3: 1 \mathrm{HNO}_{3}: \mathrm{HCl}\right.$, A.C.S. reagent grade, Spectrum Chemical Mfg. Corp., New Brunswick, NJ, USA), and filtered through a 2- $\mu \mathrm{m}$ glass fiber filter (Millipore Sigma AP2501300). The supernatant solution was diluted to $50.0 \mathrm{~mL}$ and stored in polypropylene test tubes. The samples were then analyzed using inductively coupled plasma-optical emission spectroscopy (ICP-OES). A PerkinElmer 8300 ICP-OES was used to construct calibration curves over the range of $0-400 \mathrm{mg} / \mathrm{L} \mathrm{Ba} ; 0-5.0 \mathrm{mg} / \mathrm{L} \mathrm{Cr} ; 0-50 \mathrm{mg} / \mathrm{L} \mathrm{Pb}$; and $0-0.25 \mathrm{mg} / \mathrm{L} \mathrm{Ag}$. The plasma operated at 1500 Watts of radio frequency (RF) power with argon gas flows of $10 \mathrm{~L} / \mathrm{min}$, $0.4 \mathrm{~L} / \mathrm{min}$, and $0.6 \mathrm{~L} / \mathrm{min}$ in plasma, auxiliary, and nebulizer supplies, respectively. The oranges were analyzed in three parts: the juice, the pith, and the peel. The pith and peels were dried at $60^{\circ} \mathrm{C}$ for 3 days prior to being processed as described above.

A total of seven samples of soils and leaves were collected and analyzed. In addition, 11 mandarin oranges were harvested and processed at the end of the experiment. The vector of watering days is $w=(0,20,26,31,35,39,43)$. Thus, $w=0$ represents the baseline (control) concentrations of $\mathrm{Ba}, \mathrm{Cr}, \mathrm{Pb}$, and $\mathrm{Ag}$ in the soil and leaves at the start of the experiment, i.e., when no heavy metal irrigation water had been applied yet, while $w=26$ refers to the concentrations measured after 26 waterings. Analysis of covariance (ANCOVA) was carried out to model the change in measured metal concentrations in both the soil and leaf samples as a function of the heavy metal concentration in the irrigation water (the treatment) while controlling for waterings ( $w$ ). Analysis of variance (ANOVA) was used to estimate the effects of the irrigation water concentrations on the pith, peel, and juice of the fruit. Since the sampling design was not fully balanced (the low concentration level had only seven mandarin orange plants), type II and III sums of squares were used [29]. Tukey's honest significant difference test (Tukey HSD) was applied to identify differences in means between factor level combinations. All analyses were carried out in the R statistical language and computing environment, version 3.4.3 [30]. Results are presented by metal. 


\section{Results}

The average baseline levels for the tested heavy metals are shown in Table 2. According to Bradford et al. the average soil baseline concentration in California for Ba is $509 \mathrm{mg} / \mathrm{kg}, 122 \mathrm{mg} / \mathrm{kg}$ for $\mathrm{Cr}, 23.9 \mathrm{mg} / \mathrm{kg}$ for $\mathrm{Pb}$, and $0.80 \mathrm{mg} / \mathrm{kg}$ for $\mathrm{Ag}$ [31]. Thus, all measured baseline levels for the plant soils were below the background levels generally found in Californian soils. No comparison baseline levels are available for the leaves.

Table 2. Average baseline concentration levels for $\mathrm{Ba}, \mathrm{Cr}, \mathrm{Pb}$, and $\mathrm{Ag}$ in soil and leaves.

\begin{tabular}{ccc}
\hline Metal & $\begin{array}{c}\text { Baseline Concentration in Soil } \\
(\mathbf{m g} \text { metal/kg) }\end{array}$ & $\begin{array}{c}\text { Baseline Concentration in Leaves } \\
(\mathbf{m g} \text { metal } / \mathbf{k g})\end{array}$ \\
\hline Barium & 32.609 & 100.122 \\
Chromium & 1.085 & 0.845 \\
Lead & 0.890 & 4.524 \\
Silver & 0.322 & 1.395 \\
\hline
\end{tabular}

\subsection{Barium}

Of the tested metals, Ba showed the most pronounced and consistent pattern of increase in accumulation in both the soil and the leaves (see Figure 1). The increase was largest for the high concentration water, followed by the medium and low concentration water, respectively. Concentrations increased from an average baseline level of $17.6 \mathrm{mg} / \mathrm{kg}$ with standard deviation (SD) of $1.4 \mathrm{mg} / \mathrm{kg}$ to an average of $48,086.5 \mathrm{mg} / \mathrm{kg}(\mathrm{SD}=9270 \mathrm{mg} / \mathrm{kg})$ for the high concentration water at time $w=43$. For the low watering concentrations, the increase was from $57.6 \mathrm{mg} / \mathrm{kg}$ (SD $61.8 \mathrm{mg} / \mathrm{kg}$ ) at baseline to $3674.5 \mathrm{mg} / \mathrm{kg}(\mathrm{SD}=2737.6 \mathrm{mg} / \mathrm{kg})$ at $w=43$.

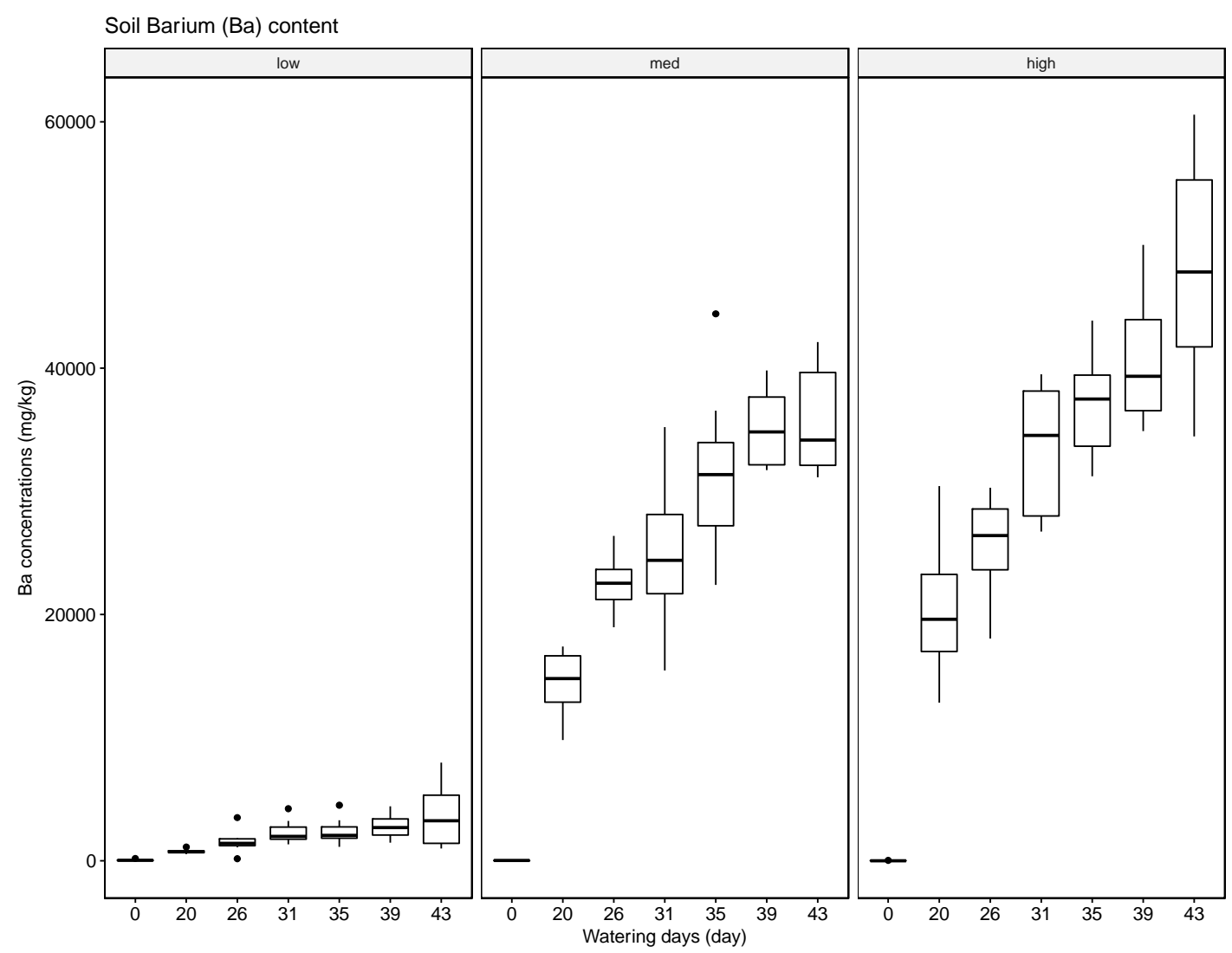

Figure 1. Boxplots of measured concentrations of $\mathrm{Ba}$ in the soil as a function of Ba concentration in the irrigation water (low, medium, high) and watering day, $w$. 
A similar pattern presented for the leaves (see Figure 2), although at a slower rate and with concentrations leveling off at $w=26$. No significant accumulation occurred the low watering concentration and there was not enough evidence for significant interactions between treatment and time.

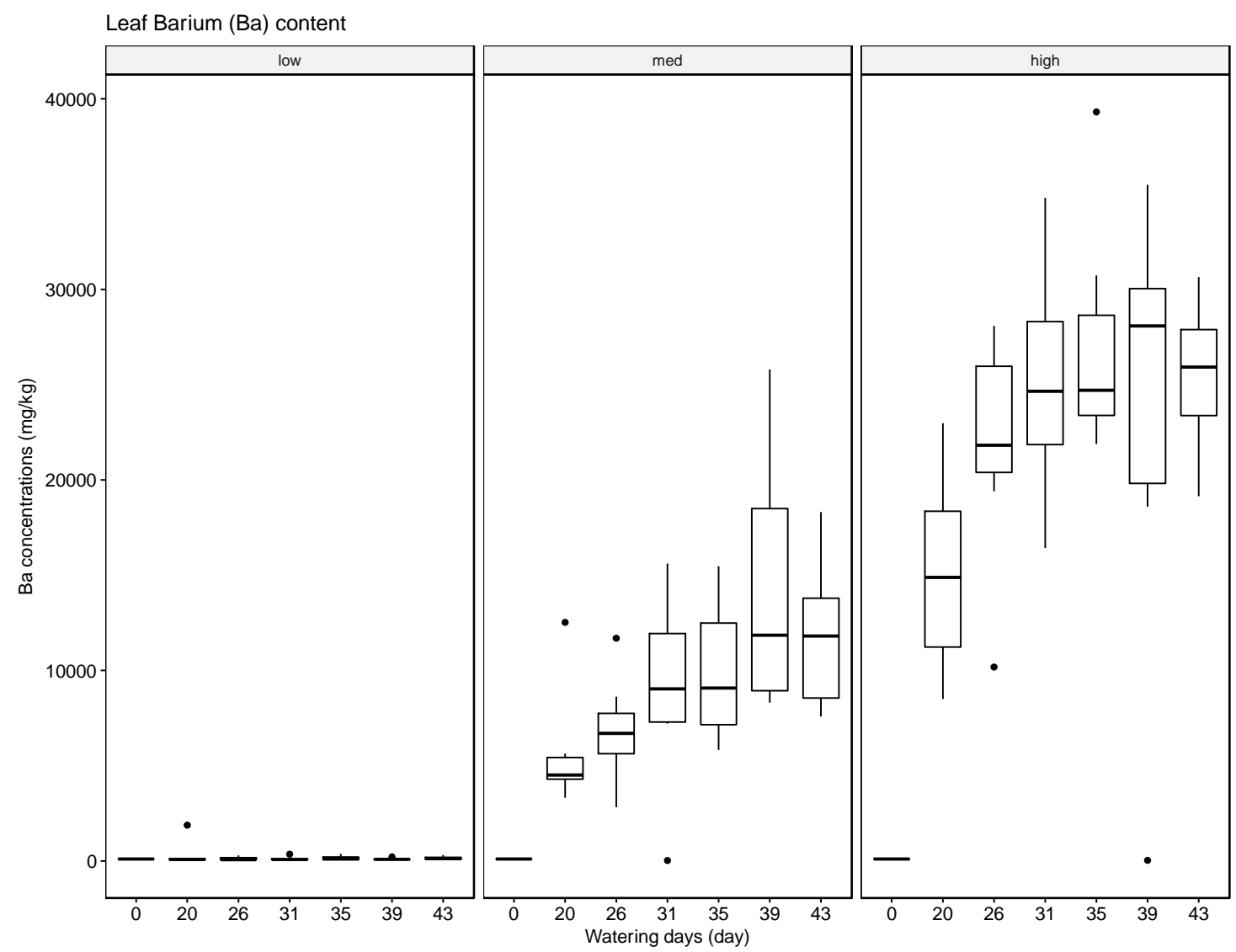

Figure 2. Boxplots of measured concentrations of $\mathrm{Ba}$ in the leaves as a function of Ba concentration in the irrigation water (low, medium, high) and watering day, $w$.

The ANCOVA results are shown in Table 3. The interaction is statistically significant and indicates different accumulation rates for the three tested concentrations.

Table 3. Summary of analysis of covariance (ANCOVA) results for Ba concentrations in the soil and the leaf samples.

\begin{tabular}{ccc}
\hline Factor & $\boldsymbol{F}$-Value & $\boldsymbol{p}$-Value \\
\hline \multicolumn{3}{c}{ Soil: } \\
\hline treatment & 465.40 & $<0.0001$ \\
waterings & 845.11 & $<0.0001$ \\
treatment:waterings & 105.95 & $<0.0001$ \\
\hline \multicolumn{3}{c}{ Leaves: } \\
\hline treatment & 182.00 & $<0.0001$ \\
waterings & 35.02 & $<0.0001$ \\
treatment:waterings & 7.72 & $<0.0001$ \\
\hline
\end{tabular}

Ba concentrations in the fruit (Figure 3) were highest for the peel (mean $=1014.2 \mathrm{mg} / \mathrm{kg}$, $\mathrm{SD}=1654.1 \mathrm{mg} / \mathrm{kg}$ ) and pith $($ mean $=834.0 \mathrm{mg} / \mathrm{kg}, \mathrm{SD}=1193.2 \mathrm{mg} / \mathrm{kg}$ ). At the high watering concentration, the peel had a mean concentration of $4544.3 \mathrm{mg} / \mathrm{kg}(\mathrm{SD}=315.5 \mathrm{mg} / \mathrm{kg})$, and the pith a 
mean of $3318.4 \mathrm{mg} / \mathrm{kg}(\mathrm{SD}=16.8 \mathrm{mg} / \mathrm{kg})$. Concentrations of Ba in the juice remained low regardless of the concentration of Ba in the irrigation water (mean $=52.8 \mathrm{mg} / \mathrm{kg}, \mathrm{SD}=56.1 \mathrm{mg} / \mathrm{kg}$ ). The ANOVA results of the effect of $\mathrm{Ba}$ watering concentrations and fruit type (peel, pith, and juice) shown in Table 4 indicate that both are highly significant and that the effect of treatment depends on the type of fruit analyzed.

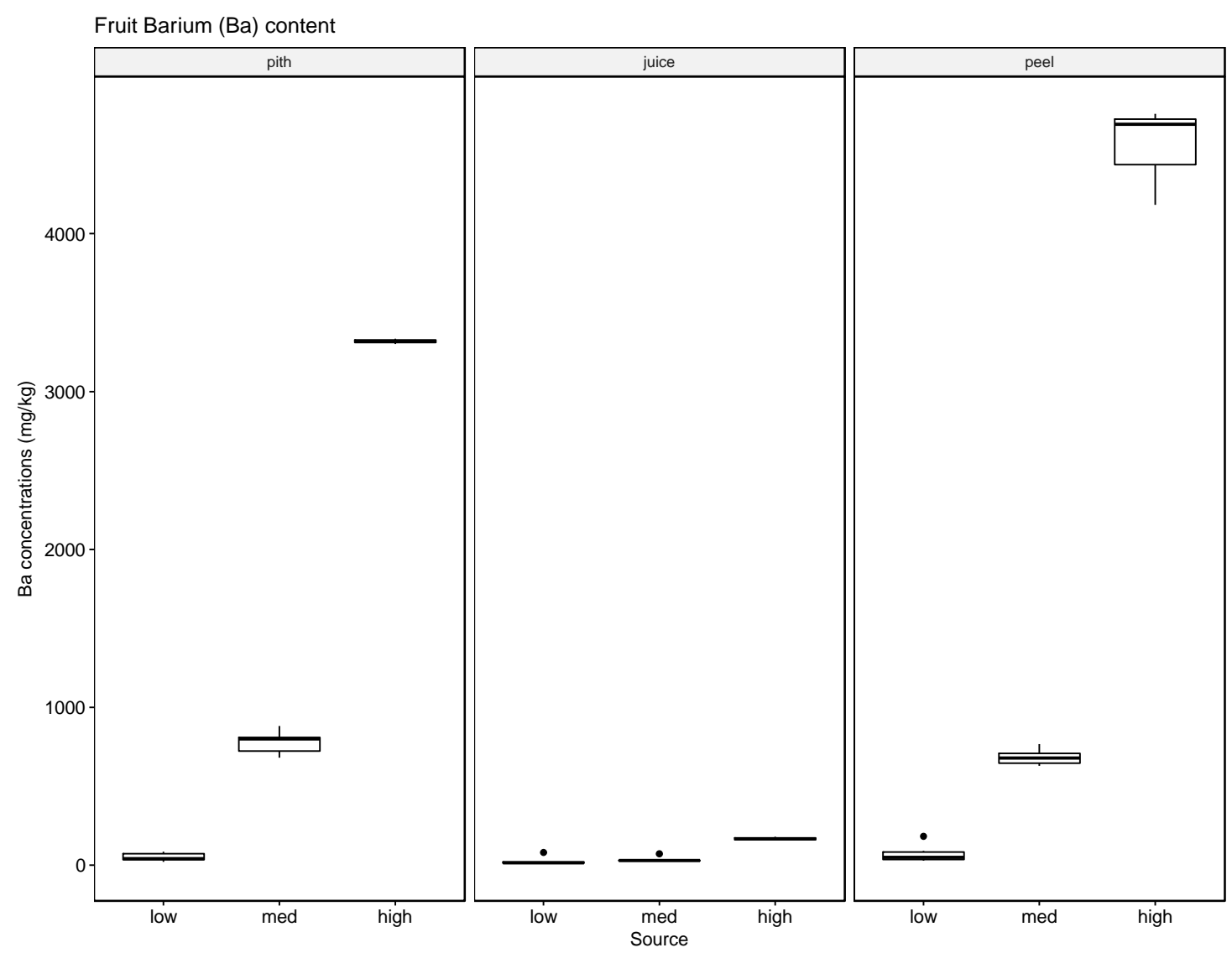

Figure 3. Boxplots of measured concentrations of Ba in the pith, juice, and peel portions of the harvested mandarin oranges as a function of Ba concentration in the irrigation water (low, medium, high).

Table 4. Summary of ANOVA for the concentrations of Ba in the fruit samples.

\begin{tabular}{ccc}
\hline Factor & $\boldsymbol{F}$-Value & $p$-Value \\
\hline treatment & 2469.77 & $<0.0001$ \\
type & 735.67 & 0.0002 \\
treatment:type & 603.81 & 0.0613 \\
\hline
\end{tabular}

\subsection{Chromium}

The measurements for total $\mathrm{Cr}$ in the soil show an increase with watering days, $w$, that levels off at $w=26$. As the boxplots in Figure 4 illustrate, the variation in measured concentrations also increased with $w\left(\mathrm{SD}_{\mathrm{w}=0}=1.2 \mathrm{mg} / \mathrm{kg}\right.$ and $\left.\mathrm{SD}_{\mathrm{w}=43}=5.7 \mathrm{mg} / \mathrm{kg}\right)$. There was little to no differentiation in soil accumulation between the three tested irrigation water concentrations.

The results for total $\mathrm{Cr}$ in the leaves are more volatile (Figure 5). There was an initial increase in measured concentration up to $w=31$, followed by a sharp drop at $w=35$, substantial rise at $w=39$, and smaller decline at $w=43$. 
The results for the ANCOVA with watering days as the continuous variable are shown in Table 5. All main effects and interactions for the soil are statistically significant, while in the leaf samples only the treatment effect is significant $(\alpha=0.05)$.

For the harvested oranges, the highest total $\mathrm{Cr}$ concentrations were measured in the peel (mean $=0.66 \mathrm{mg} / \mathrm{kg}, \mathrm{SD}=0.44 \mathrm{mg} / \mathrm{kg}$ ), followed by the pith (mean $=0.30 \mathrm{mg} / \mathrm{kg}, \mathrm{SD}=0.08 \mathrm{mg} / \mathrm{kg}$ ) and the juice (mean $=0.20 \mathrm{mg} / \mathrm{kg}, \mathrm{SD}=0.11 \mathrm{mg} / \mathrm{kg}$ ) (see Figure 6 and Table 6). These differences are statistically significant. While average concentrations increased with the level of watering concentrations for the pith (not for the peel and juice), F-tests in the ANOVA and Tukey's HSD tests reveal no statistically significant differences for treatment and treatment:type interaction.

Table 5. Summary of ANCOVA for total Cr concentrations in the soil and the leaf samples.

\begin{tabular}{ccc}
\hline Factor & $\boldsymbol{F}$-Value & $p$-Value \\
\hline & Soil: & \\
\hline treatment & 28.69 & $<0.0001$ \\
waterings & 359.05 & $<0.0001$ \\
treatment:waterings & 5.667 & $<0.001$ \\
\hline & Leaves: & \\
\hline treatment & 3.76 & 0.0129 \\
waterings & 2.88 & 0.0924 \\
treatment:waterings & 0.60 & 0.6181 \\
\hline
\end{tabular}

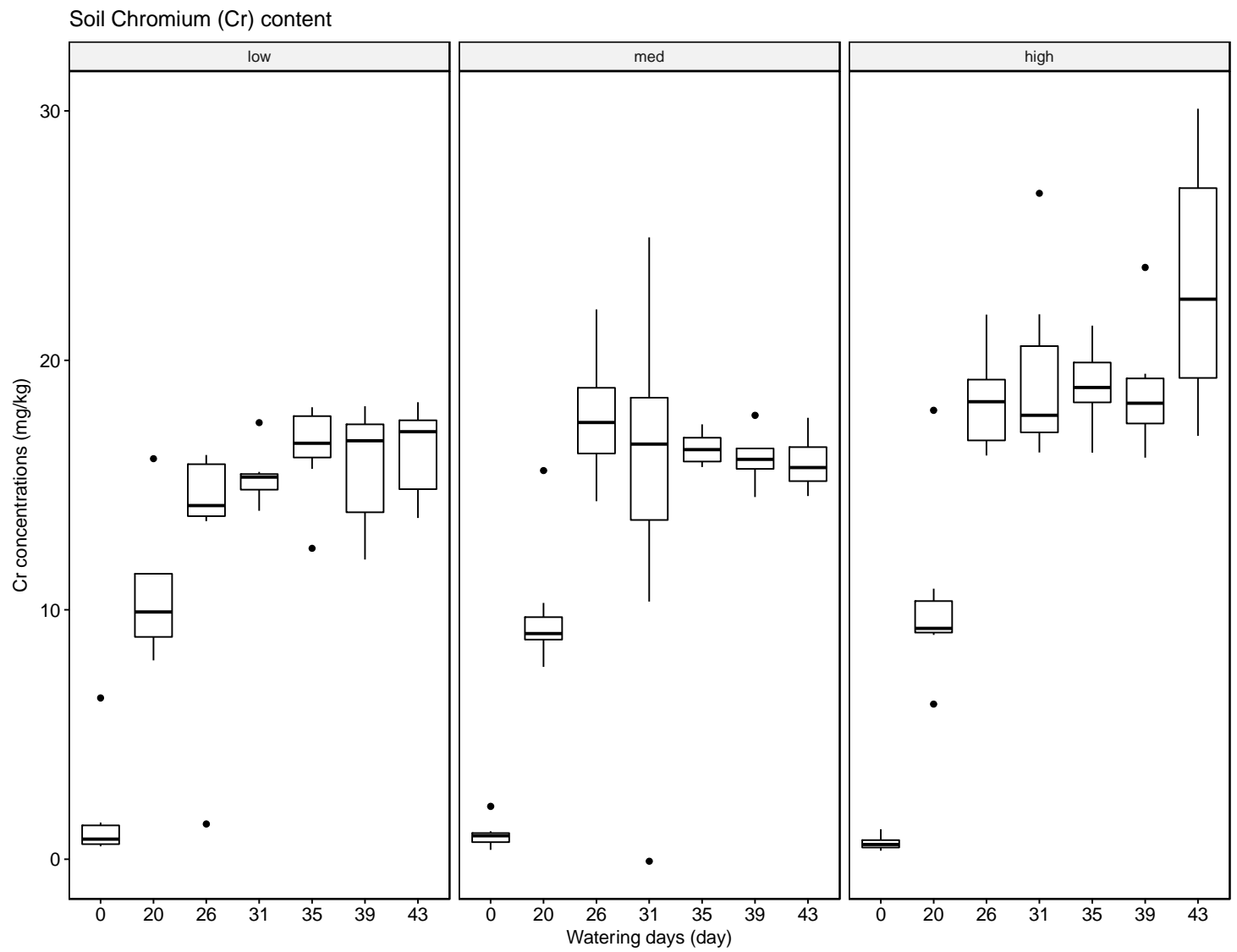

Figure 4. Boxplots of measured concentrations of total $\mathrm{Cr}$ in the soil as a function of $\mathrm{Cr}$ (III) concentration in the irrigation water (low, medium, high) and watering day, $w$. 


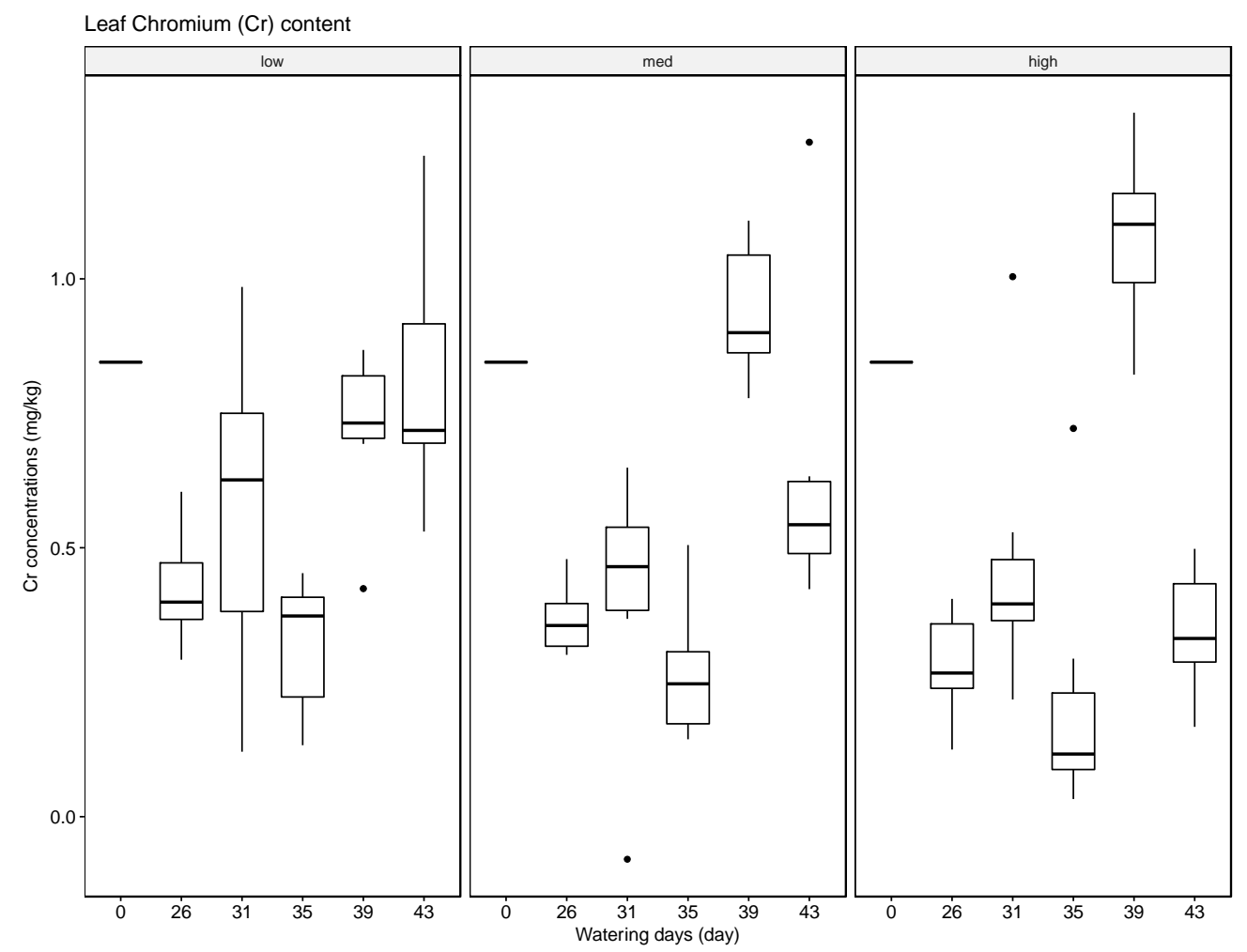

Figure 5. Boxplots of measured concentrations of total $\mathrm{Cr}$ in the leaves as a function of $\mathrm{Cr}(\mathrm{III})$ concentration in the irrigation water (low, medium, high) and watering day, $w$.

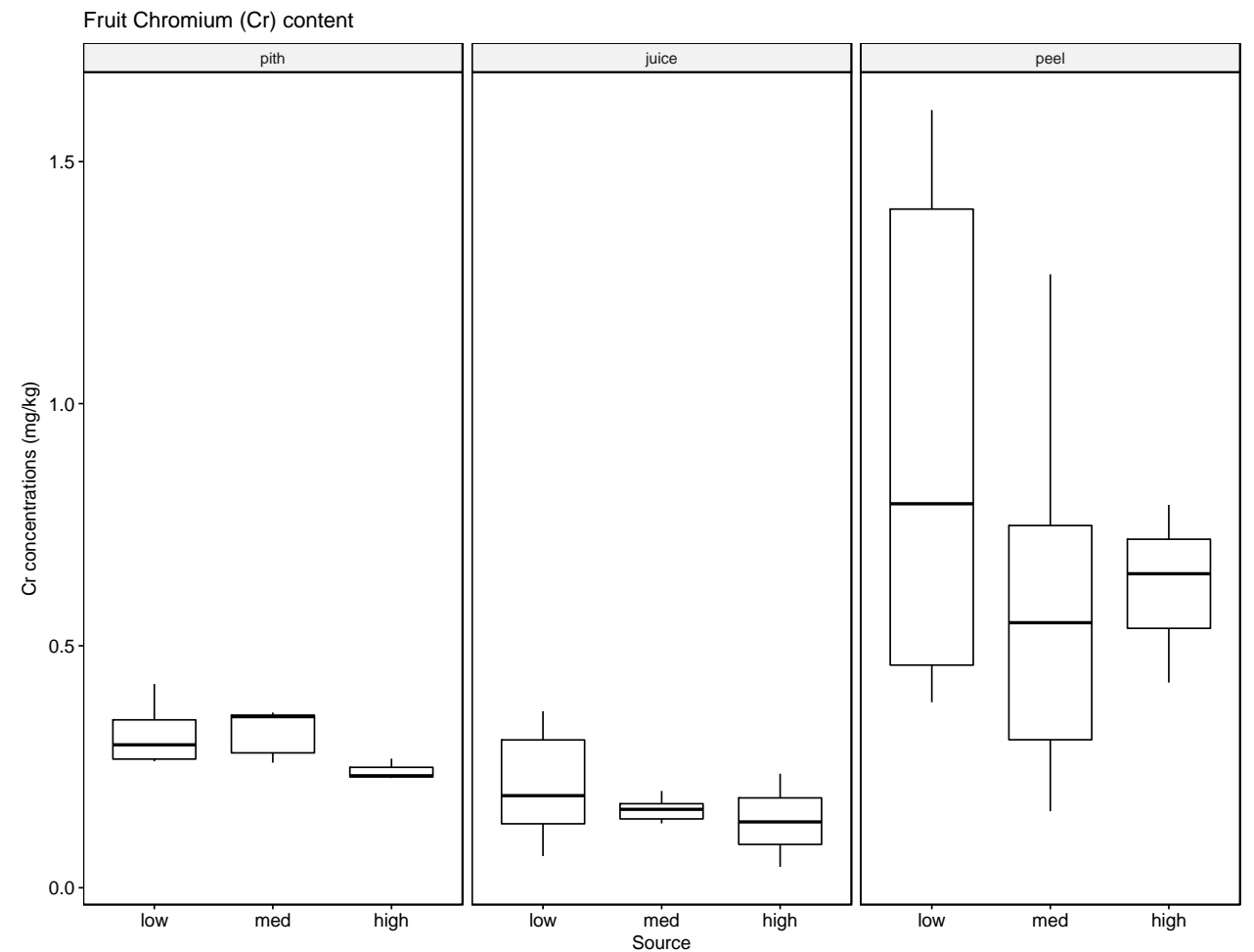

Figure 6. Boxplots of measured concentrations of total $\mathrm{Cr}$ in the pith, juice, and peel portions of the harvested mandarin oranges as a function of $\mathrm{Cr}$ (III) concentration in the irrigation water (low, medium, high). 
Table 6. Summary of ANOVA for Cr concentrations in fruit samples.

\begin{tabular}{ccc}
\hline Factor & $\boldsymbol{F}$-Value & $\boldsymbol{p}$-Value \\
\hline treatment & 1.3142 & 0.2831 \\
type & 15.176 & $<0.0001$ \\
treatment:type & 1.4861 & 0.2077 \\
\hline
\end{tabular}

\subsection{Lead}

The results for $\mathrm{Pb}$ indicate that accumulation in the soil is associated with watering days, $w$, and the concentration of $\mathrm{Pb}$ in the irrigation water (see Figure 7). At low and medium irrigation water concentrations, the soil concentration of $\mathrm{Pb}$ increased slowly and steadily (mean low $=194.0 \mathrm{mg} / \mathrm{kg}$, $\mathrm{SD}_{\text {low }}=212.8 \mathrm{mg} / \mathrm{kg}$, mean $_{\text {med }}=309.8 \mathrm{mg} / \mathrm{kg}, \mathrm{SD}_{\text {med }}=382.9 \mathrm{mg} / \mathrm{kg}$ ), while for the high concentration water the slope of accumulation was larger, but also subject to greater variation (mean $=866.8 \mathrm{mg} / \mathrm{kg}$, $\mathrm{SD}=943.5 \mathrm{mg} / \mathrm{kg}$ ). The leaves (Figure 8) showed little accumulation up to $w=31$. Beyond this time point, concentrations in the leaves rose but at a markedly increased between-plant variance. No systematic differences between low, medium, and high irrigation water concentrations were detected using Tukey's HSD test. The ANCOVA results are shown in Table 7 and, as was the case for $\mathrm{Ba}$, the slopes for the soil concentrations for time vary based on treatment.

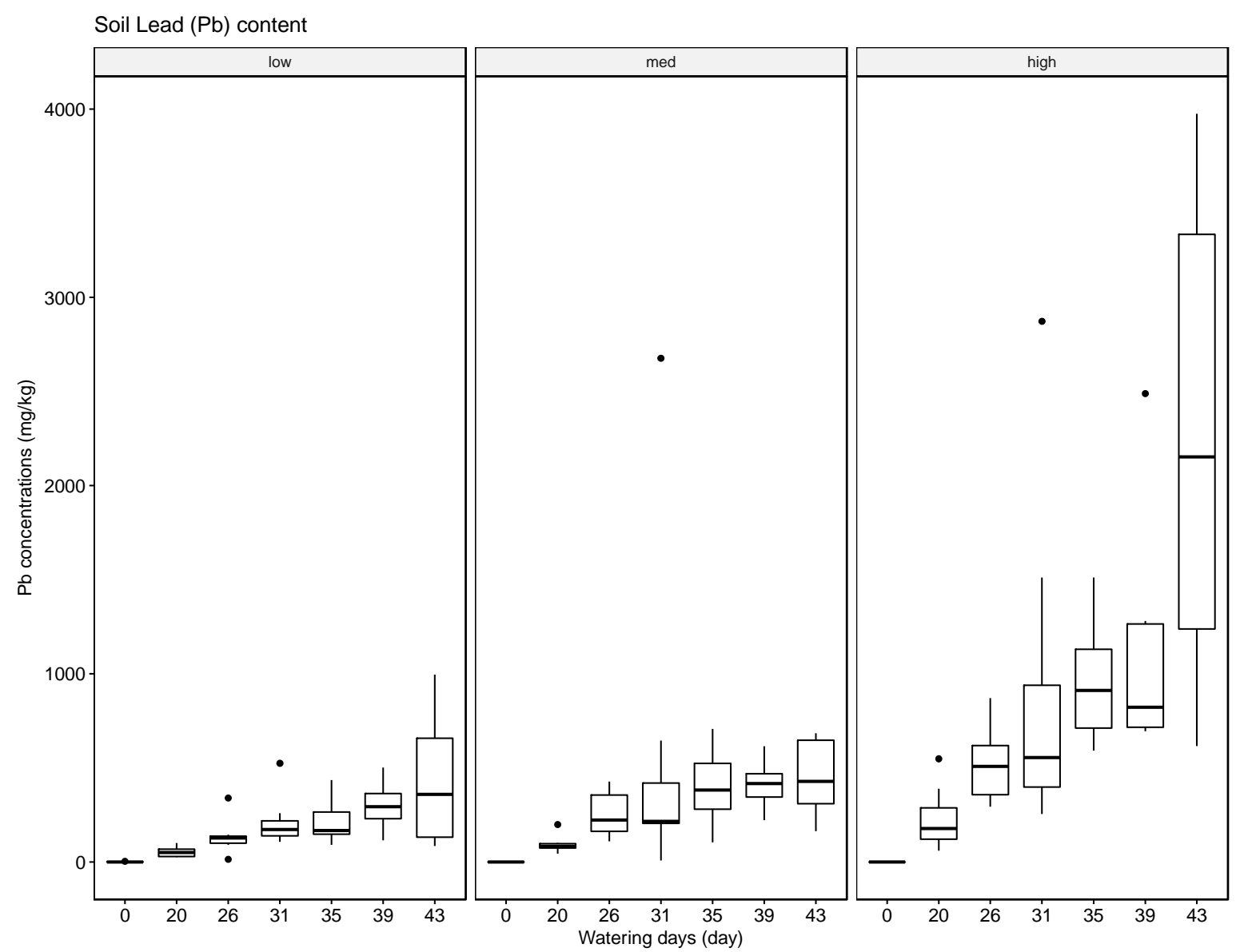

Figure 7. Boxplots of measured concentrations of $\mathrm{Pb}$ in the soil as a function of $\mathrm{Pb}$ concentration in the irrigation water (low, medium, high) and watering day, $w$. 


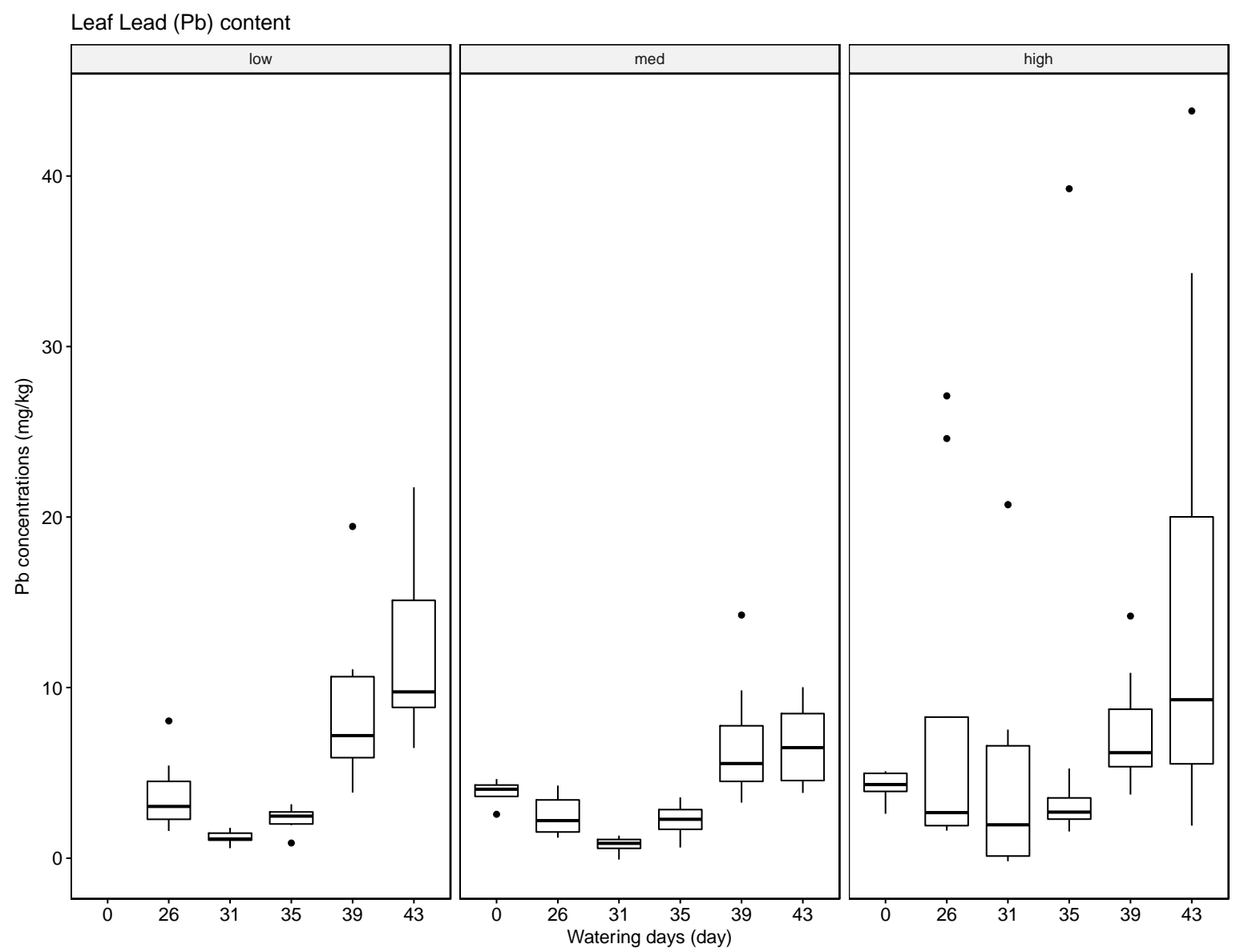

Figure 8. Boxplots of measured concentrations of $\mathrm{Pb}$ in the leaves as a function of $\mathrm{Pb}$ concentration in the irrigation water (low, medium, high) and watering day, $w$.

Table 7. Summary of ANCOVA for Pb concentrations in the soil and the leaf samples.

\begin{tabular}{ccc}
\hline Factor & $\boldsymbol{F}$-Value & $p$-Value \\
\hline & Soil: \\
\hline treatment & 21.208 & $<0.0001$ \\
waterings & 57.288 & $<0.0001$ \\
treatment:waterings & 9.857 & $<0.0001$ \\
\hline \multicolumn{3}{c}{ Leaves: } \\
\hline treatment & 3.26 & 0.0238 \\
waterings & 11.43 & 0.001 \\
treatment:waterings & 0.87 & 0.4572 \\
\hline
\end{tabular}

Comparatively high levels of variation mark the $\mathrm{Pb}$ concentrations in the pith, juice, and peel for all three tested watering concentrations (Figure 9). Average concentrations were highest for the fruit material but were not statistically significant. 
Fruit Lead $(\mathrm{Pb})$ content

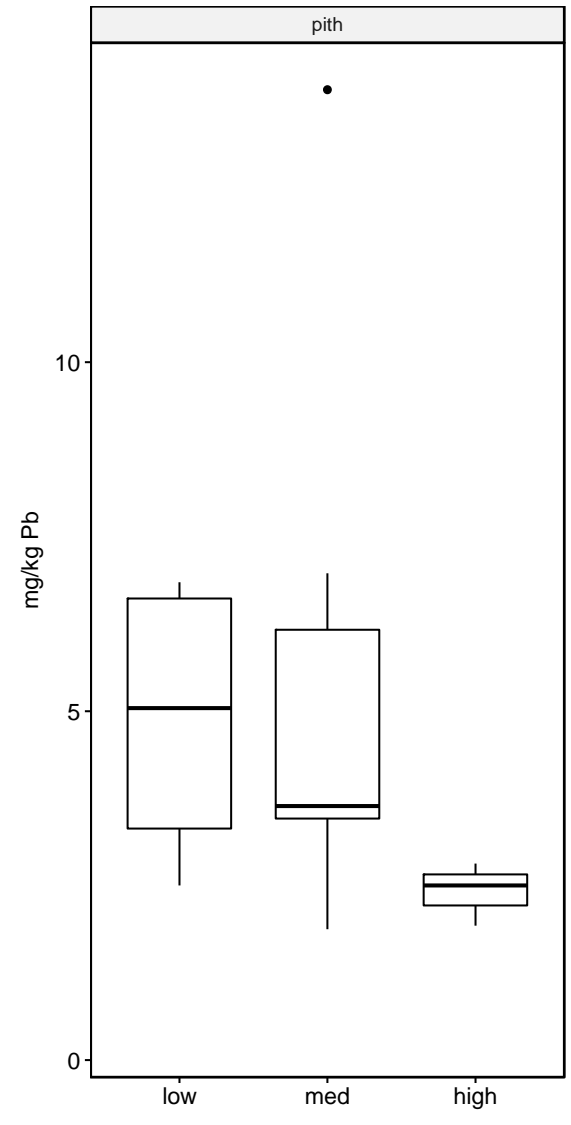

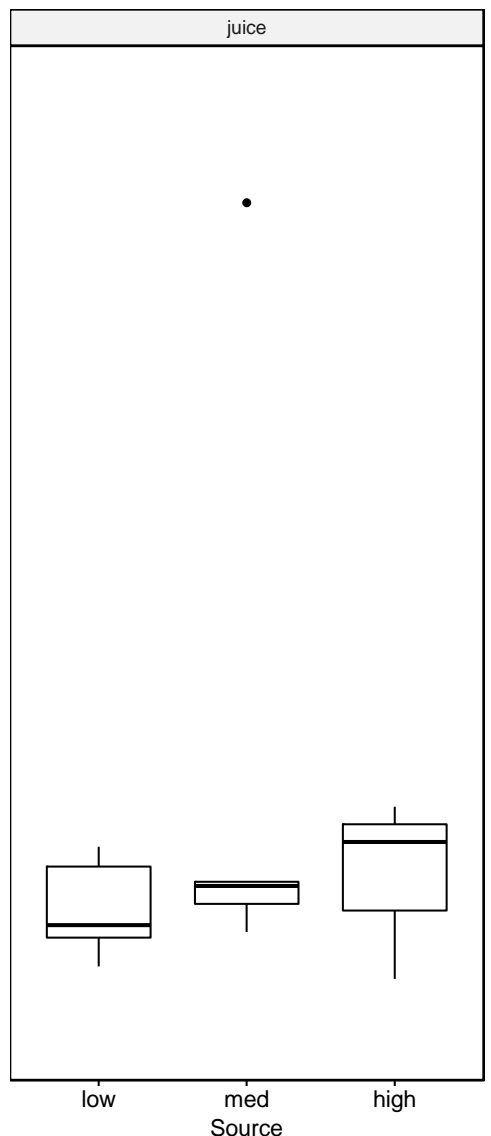

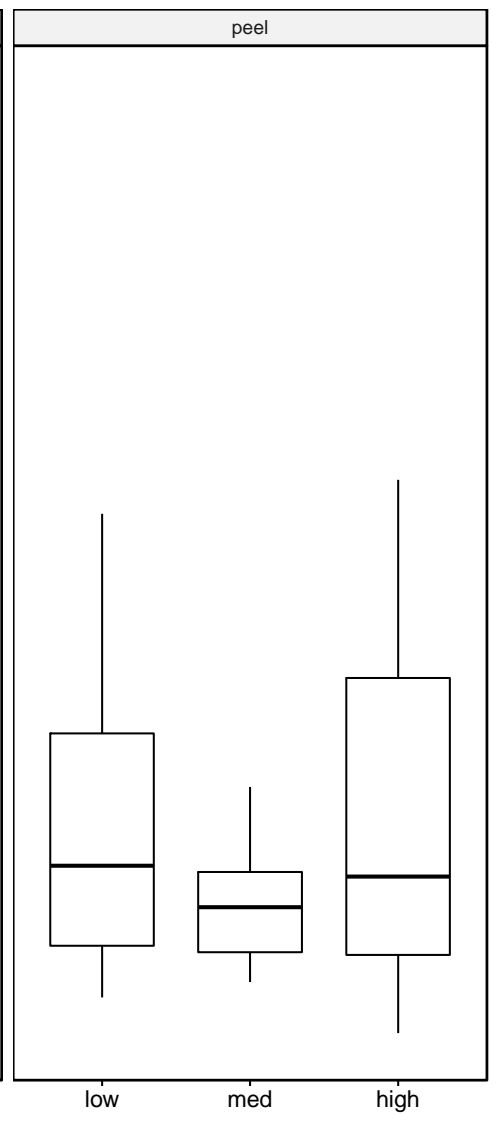

Figure 9. Boxplots of measured concentrations of $\mathrm{Pb}$ in the pith, juice, and peel portions of the harvested mandarin oranges as a function of $\mathrm{Pb}$ concentration in the irrigation water (low, medium, high).

\subsection{Silver}

Silver concentrations show no clear detectable patterns over time or watering concentrations (see Supplementary Material Figures S1 and S2) for both soil and leaves. While baseline soil and leaf concentrations were low and subsequent sampling times detected significant increases, they remained approximately steady over time. Furthermore, the results for the medium and high watering concentrations were indistinguishable, while low watering concentrations on average yielded lower Ag soil concentrations.

For the harvested mandarin oranges, Ag concentrations appeared to increase with watering concentrations in the pith, but not in the juice or the peel, where they remained well below $1 \mathrm{mg} / \mathrm{kg}$ (see Supplementary Material Figure S3).

\section{Discussion}

The study presents the result of a controlled experiment of the accumulation of four heavy metals $(\mathrm{Ba}, \mathrm{Cd}, \mathrm{Pb}, \mathrm{Ag})$ in the soil, leaves, and fruit of 23 mandarin orange trees that were irrigated with water containing concentrations of these elements at three levels that are representative of OPW conditions. The study's goals were to detect the soil and plant (leaves, fruit) concentrations of these elements, which are frequently found in similar concentrations in oilfield produced water (OPW), and to examine if there were detectable trends over time and as a function of the metals' concentration in the irrigation water. In the absence of federal (and state) regulations on the permissible concentrations of these and other compounds found in OPW, it is of interest to learn about their fate when OPW is reused for 
agricultural crop irrigation on a frequent basis, as is the case in several water districts in California's agriculturally important Central Valley.

The results indicate that soils can accumulate several of the tested elements, in particular $\mathrm{Ba}$, but to a lesser extent also $\mathrm{Pb}$ and $\mathrm{Cr}$, and that generally the accumulated amounts are higher when these heavy metals are supplied in high concentrations in the irrigation water. The results for $\mathrm{Ag}$ were inconclusive. Compared with the soil samples, the leaf material showed consistently lower concentrations of the tested elements. The most significant uptake was observed for Ba at the high concentration level. This finding is supported by some reports in the literature that green leafy material, with the exception of leafy produce such as spinach and lettuce and senescing leaves in trees such as poplar, tends to store little heavy metals [32-34].

There is very little peer-reviewed literature on the concentrations of the tested heavy metals in soils treated with OPW wastewater and hence little data available to compare our concentrations against. Odeigah et al. (1997) tested the general toxicity and genotoxicity of OPW on the bulbs of Allium cepa L. and found significant phytotoxic and chromosomal effects [35]. Pichtel (2016) gives an overview on the chemicals contained in OPW and their effects on soil health and productivity, while a grey literature report assesses how OPW use could impact the long-term health of agricultural production in California's Central Valley [6,36]. Instead, most of the OPW literature focuses on treatment procedures and technologies prior to its application to farm fields.

All tested metals have known adverse human health effects that range from mild discomforts to serious organ damage and even death. For example, Ba (in soluble form), $\mathrm{Cr}$, and $\mathrm{Pb}$ ingested in small to moderate concentrations can impact the digestive and respiratory tracts, the musculoskeletal and neurological systems, and the reproductive organs. The effects depend on the exposure route, frequency, and magnitude of exposure, as well as the chemical formulation of the metal (e.g., soluble versus insoluble Ba). Although the OPW in this study is used for crop irrigation and does not directly enter drinking water sources, it is illustrative to compare the measured concentrations with applicable drinking water standards, because of the risk of exposure to consumers of the edible crop. For Ba, the federal Maximum Contaminant Level (MCL) is $2.0 \mathrm{mg} / \mathrm{L}$, for Pb the EPA specified an Action Level of $0.015 \mathrm{mg} / \mathrm{L}$. The MCL for total $\mathrm{Cr}$ is $0.1 \mathrm{mg} / \mathrm{L}$, and for Ag the federal Secondary Drinking Water Standard is $2.0 \mathrm{mg} / \mathrm{L}$ [37]. The soil, leaf, and fruit concentrations measured for the four metals frequently exceeded these thresholds, noticeably at the medium and high watering concentrations. The potential exceedance of public health standards is especially concerning for the fruit measurements. The pith appears to be the most likely to accumulate the tested metals at concentrations potentially endangering the health of the consumer with concentrations for Ba ranging from $21.57 \mathrm{mg} / \mathrm{kg}$ to $4758.25 \mathrm{mg} / \mathrm{kg}$, for Cr from $0.13 \mathrm{mg} / \mathrm{kg}$ to $1.61 \mathrm{mg} / \mathrm{kg}$, for Pb from $0.43 \mathrm{mg} / \mathrm{kg}$ to $8.36 \mathrm{mg} / \mathrm{kg}$, and for $\mathrm{Ag}$ from $0.10 \mathrm{mg} / \mathrm{kg}$ to $0.91 \mathrm{mg} / \mathrm{kg}$.

It is noteworthy in this study that the concentrations reported are for total $\mathrm{Ba}, \mathrm{Cr}, \mathrm{Pb}$, and $\mathrm{Ag}$. While the heavy metals were applied in the watering solutions as the soluble species, the acid digestion and ICP-OES analysis provides no insights on soluble fraction, bioavailability, or oxidation state, i.e., $\mathrm{Cr}(\mathrm{III})$ versus $\mathrm{Cr}(\mathrm{VI})$, in soil, leaf, or fruit. Available research highlights the need for more differentiated study of the composition of the OPW and heavy metal speciation in soil and plant matter [25,26,38-41]. In particular, health risk assessments benefit from estimating the bioavailable fractions of the metals, which are generally smaller than the accessible fraction and the total concentration of the soluble salts. For example, in assessing the comparative toxicity potentials (CTPs) of $\mathrm{Cu}$ and $\mathrm{Ni}$, the main influencing factors were the metals' $\mathrm{pH}$ dependency with respect to dissolution and complexation; differences in metal availability for partitioning to the solution phase due to differences in solid-phase reactivity; and susceptibility of metal sorption, speciation, and toxicity to variations in soil chemistry parameters [25]. A separate study of the bioavailability of $\mathrm{Cd}, \mathrm{Co}, \mathrm{Cu}, \mathrm{Ni}, \mathrm{Pb}$, and $\mathrm{Zn}$ found that the emission source and aging mechanisms in the soil can also contribute to the metals' reactivity [26]. We intend to examine these issues in additional studies. 
The study has some additional limitations. The sample size of 23 citrus plants is relatively small and the experiment was conducted on potted plants and not in an orchard in the Central Valley with actual OPW-supplemented irrigation water. Thus, the typical conditions, including soil cycling, soil types, and hydrological movements of irrigation water could not be fully replicated and no soil characterization and analysis of the transport mechanisms of the heavy metals in the soils and plants were done. These should be part of follow-up studies. The study also had a limited duration (June 2017 through March 2018) and was interrupted by two periods of watering with freshwater only. However, this watering, and a small number of precipitation events in the winter months, are assumed to have flushed out some of the metals that had accumulated in the soil as opposed to further enrich it. Finally, due to the time limits on the study, mandarin oranges could only be harvested and tested once.

\section{Conclusions}

The present study of the uptake of the heavy metals $\mathrm{Ba}, \mathrm{Cr}, \mathrm{Pb}$, and $\mathrm{Ag}$ contained in soluble form in irrigation water by the soil and the leaves and fruit of mandarin orange plants allows the following conclusions. First, the elevated concentrations of $\mathrm{Ba}, \mathrm{Cr}$, and $\mathrm{Pb}$ indicate that a full characterization of their toxicity potentials is needed within the OPW context. The field sampling conducted by the Food Safety Expert Panel for citrus, almonds, pistachios, table grapes, and garlic tested for 108 elements and chemical compounds and detected 16 in the fruit and seed samples, among them $\mathrm{Ba}, \mathrm{Cu}, \mathrm{Mo}, \mathrm{Ni}, \mathrm{Sr}$, and $\mathrm{Zn}$. In several cases, concentrations of these metals in the treated crop were statistically higher than in the controls, but were still judged to be "non-alarming." The present study indicates that field sampling, such as the studies conducted for the Food Safety Expert Panel, should be continued at least for citrus fruit to reaffirm that there is no risk for consumers. The results, furthermore, signal the need to conduct a systematic soil study to assess the risk of heavy metal accumulation for soil and crop health. The Regional Water Quality Control Board is in the process of planning additional studies for the new growing season to supplement the existing data. These studies aim to include root vegetables such as garlic, potatoes, and carrots, which may have a higher propensity to store heavy metals and other contaminants than tree crops. The present study suggests that soil analysis should be included as well.

The question of whether OPW use in agriculture poses risks to consumers of the impacted crops also requires testing the long-term effects of OPW application, because crops with very low to low concentrations of compounds with known adverse health effects may pose risks if the crop is consumed in large-enough quantities by consumers (e.g., the increase in consumption of mandarin oranges between October-February).

Since OPW chemical composition can change over time, often within short time periods, it remains advisable in the short term that OPW water quality testing continues for at least key contaminants that carry substantial health risks at even small concentrations, such as heavy metals, BTEX, and radioactive isotopes.

Adding more advanced treatment of OPW to regular OPW, crop, and soil quality monitoring can further ensure that harmful and toxic elements and chemicals do not reach agricultural products, especially those aimed for human consumption. With sufficient safeguards in place OPW could be considered a supplemental water resource for California's Central Valley farms and hence make for a mutually beneficial partnership between the oil and agricultural industries in the region.

Supplementary Materials: The following are available online at http:/ /www.mdpi.com/2071-1050/10/5/1493/ s1: R Markdown Scripts for $\mathrm{Ag}, \mathrm{Ba}, \mathrm{Cr}$, and $\mathrm{Pb}$. Data files for $\mathrm{Ag}, \mathrm{Ba}, \mathrm{Cr}$, and $\mathrm{Pb}$. Figure S1: Boxplots of measured concentrations of $\mathrm{Ag}$ in the soil as a function of $\mathrm{Ag}$ concentration in the irrigation water (low, medium, high) and sampling time, $t$; Figure S2: Boxplots of measured concentrations of Ag in the leaves as a function of Ag concentration in the irrigation water (low, medium, high) and sampling time, $t$; Figure S3: Boxplots of measured concentrations of $\mathrm{Ag}$ in the pith, juice, and peel portions of the harvested mandarin oranges as a function of $\mathrm{Ag}$ concentration in the irrigation water (low, medium, high).

Author Contributions: T.S. and H.v.R. conceived and planned the study and ran the statistical analysis. T.S. drafted the manuscript and H.v.R. and A.Z. provided edits. A.Z. and H.v.R. processed and analyzed the samples. V.C. and B.P. assisted with solution preparation, watering, and sample preparation. 
Acknowledgments: The authors wish to thank Penny Manisco and Daniel Guerra of the Harvey Mudd College Chemistry Department, Troy Hansgen and the college grounds crew, Marc los Huertos, Jade Star Lackey, and Kyle McCarty (Pomona College, Claremont, CA, USA), and Colin Robins and Branwen Williams (Keck Science Department of Claremont McKenna, Pitzer, and Scripps College, Claremont, CA, USA) for their help in conducting the study. Funding was provided by the Hixon Center for Sustainable Environmental Design, the Office of Community Engagement through the Nathaniel Prize, and NSF MRI 1429620 for the ICP-OES instrument.

Conflicts of Interest: The authors declare that they have no conflicts of interest.

\section{References}

1. Energy Information Administration. Petroleum \& Other Liquids, Crude Oil Production. Available online: https://www.eia.gov/dnav/pet/pet_crd_crpdn_adc_mbbl_a.htm (accessed on 3 April 2018).

2. Fakhru'l-Razi, A.; Pendashteh, A.; Abdullah, L.C.; Biak, D.R.A.; Madaeni, S.S.; Abidin, Z.Z. Review of technologies for oil and gas produced water treatment. J. Hazard. Mater. 2009, 170, 530-551. [CrossRef] [PubMed]

3. Stephenson, M.T. A survey of produced water studies. In Produced Water; Springer: Boston, MA, USA, 1992; pp. 1-11.

4. Chittick, E.A.; Srebotnjak, T. An analysis of chemicals and other constituents found in produced water from hydraulically fractured wells in California and the challenges for wastewater management. J. Environ. Manag. 2017, 204, 502-509. [CrossRef] [PubMed]

5. Benko, K.L.; Drewes, J.E. Produced water in the Western United States: Geographical distribution, occurrence, and composition. Environ. Eng. Sci. 2008, 25, 239-246. [CrossRef]

6. Heberger, M.; Donnelly, K. Oil, Food, and Water: Challenges and Opportunities for California Agriculture; Pacific Institute: Oakland, CA, USA, 2015.

7. Cawelo Water District. Available online: http://www.cawelowd.org/PrdWater.html (accessed on 3 April 2018).

8. Gunderson, J. Water Reuse Gains Traction in Conventional Oil and Gas Industry; Industrial WaterWorld: Tulsa, OK, USA, 2018; Volume 16. Available online: http:/ / www.waterworld.com/articles/iww/print/volume-16/ issue-5/features/water-reuse-gains-traction-in-conventional-oil-and-gas.html (accessed on 3 April 2018).

9. California Water Boards, Central Valley Region. Oil Fields-Food Safety. Available online: https://www. waterboards.ca.gov/centralvalley/water_issues/oil_fields/food_safety/(accessed on 3 April 2018).

10. USDA, Natural Resources Conservation Service (2000). Heavy Metal Soil Contamination. Available online: https:/ / www.nrcs.usda.gov/Internet/FSE_DOCUMENTS/nrcs142p2_053279.pdf (accessed on 3 April 2018).

11. Oliveira, A.; Pampulha, M.E. Effects of long-term heavy metal contamination on soil microbial characteristics. J. Biosci. Bioeng. 2006, 102, 157-161. [CrossRef] [PubMed]

12. Obiajunwa, E.I.; Pelemo, D.A.; Owolabi, S.A.; Fasasi, M.K.; Johnson-Fatokun, F.O. Characterisation of heavy metal pollutants of soils and sediments around a crude-oil production terminal using EDXRF. Nucl. Instrum. Methods Phys. Res. Sect. B Beam Interact. Mater. Atoms 2002, 194, 61-64. [CrossRef]

13. Mulligan, C.N.; Yong, R.N.; Gibbs, B.F. Remediation technologies for metal-contaminated soils and groundwater: An evaluation. Eng. Geol. 2001, 60, 193-207. [CrossRef]

14. Alloway, B.J. Sources of heavy metals and metalloids in soils. In Heavy Metals in Soils; Springer: Dordrecht, The Netherlands, 2013; pp. 11-50.

15. Järup, L. Hazards of heavy metal contamination. Br. Med. Bull. 2003, 68, 167-182. [CrossRef] [PubMed]

16. Sparks, D.L. Environmental Soil Chemistry; Academic Press: San Diego, CA, USA; London, UK, 2003.

17. Fliessbach, A.; Martens, R.; Reber, H.H. Soil microbial biomass and microbial activity in soils treated with heavy metal contaminated sewage sludge. Soil Biol. Biochem. 1994, 26, 1201-1205. [CrossRef]

18. Rattan, R.K.; Datta, S.P.; Chhonkar, P.K.; Suribabu, K.; Singh, A.K. Long-term impact of irrigation with sewage effluents on heavy metal content in soils, crops and groundwater-A case study. Agric. Ecosyst. Environ. 2005, 109, 310-322. [CrossRef]

19. Khan, A.G.; Kuek, C.; Chaudhry, T.M.; Khoo, C.S.; Hayes, W.J. Role of plants, mycorrhizae and phytochelators in heavy metal contaminated land remediation. Chemosphere 2000, 41, 197-207. [CrossRef]

20. Pontoni, L.; van Hullebusch, E.D.; Fabbricino, M.; Esposito, G.; Pirozzi, F. Assessment of trace heavy metals dynamics during the interaction of aqueous solutions with the artificial OECD soil: Evaluation of the effect of soil organic matter content and colloidal mobilization. Chemosphere 2016, 163, 382-391. [CrossRef] [PubMed] 
21. Pontoni, L.; van Hullebusch, E.D.; Pechaud, Y.; Fabbricino, M.; Esposito, G.; Pirozzi, F. Colloidal Mobilization and Fate of Trace Heavy Metals in Semi-Saturated Artificial Soil (OECD) Irrigated with Treated Wastewater. Sustainability 2016, 8, 1257. [CrossRef]

22. Toze, S. Reuse of effluent water-Benefits and risks. Agric. Water Manag. 2006, 80, 147-159. [CrossRef]

23. Khan, S.; Cao, Q.; Zheng, Y.M.; Huang, Y.Z.; Zhu, Y.G. Health risks of heavy metals in contaminated soils and food crops irrigated with wastewater in Beijing, China. Environ. Pollut. 2008, 152, 686-692. [CrossRef] [PubMed]

24. Jung, M.C. Heavy Metal Concentrations in Soils and Factors Affecting Metal Uptake by Plants in the Vicinity of a Korean Cu-W Mine. Sensors 2008, 8, 2413-2423. [CrossRef] [PubMed]

25. Owsianiak, M.; Rosenbaum, R.K.; Huijbregts, M.A.; Hauschild, M.Z. Addressing geographic variability in the comparative toxicity potential of copper and nickel in soils. Environ. Sci. Technol. 2013, 47, 3241-3250. [CrossRef] [PubMed]

26. Owsianiak, M.; Holm, P.E.; Fantke, P.; Christiansen, K.S.; Borggaard, O.K.; Hauschild, M.Z. Assessing comparative terrestrial ecotoxicity of $\mathrm{Cd}, \mathrm{Co}, \mathrm{Cu}, \mathrm{Ni}, \mathrm{Pb}$, and $\mathrm{Zn}$ : The influence of aging and emission source. Environ. Pollut. 2015, 206, 400-410. [CrossRef] [PubMed]

27. Stringfellow, W. Preliminary Analysis of 2017 Crop Data. Presentation at the Food Safety Panel, Meeting of the Food Safety Expert Panel Central Valley Regional Water Quality Control Board, Rancho Cordova, CA, USA, 24 January 2018. Available online: https://www.waterboards.ca.gov/rwqcb5/water_issues/oil_ fields/food_safety/meetings/2018_0124_crop_sampling_update.pdf (accessed on 3 April 2018).

28. U.S. Environmental Protection Agency (EPA). Hydraulic Fracturing for Oil and Gas: Impacts from the Hydraulic Fracturing Water Cycle on Drinking Water Resources in the United States; Final Report; EPA/600/R-16/236F; U.S. Environmental Protection Agency: Washington, DC, USA, 2016.

29. Shaw, R.G.; Mitchell-Olds, T. ANOVA for unbalanced data: An overview. Ecology 1993, 74, 1638-1645. [CrossRef]

30. R Core Team. R: A Language and Environment for Statistical Computing; R Foundation for Statistical Computing: Vienna, Austria, 2013; Available online: http:/ / r-project.org/ (accessed on 8 May 2018).

31. Bradford, G.R.; Chang, A.C.; Page, A.L.; Bakhtar, D.; Frampton, J.A.; Wright, H. Background Concentrations of Trace and Major Elements in California Soils; Kearney Foundation of Soil Science, Division of Agriculture and Natural Resources, University of California: Riverside, CA, USA, 1996; pp. 1-32.

32. Dahmani-Muller, H.; Van Oort, F.; Gelie, B.; Balabane, M. Strategies of heavy metal uptake by three plant species growing near a metal smelter. Environ. Pollut. 2000, 109, 231-238. [CrossRef]

33. Laureysens, I.; Blust, R.; De Temmerman, L.; Lemmens, C.; Ceulemans, R. Clonal variation in heavy metal accumulation and biomass production in a poplar coppice culture: I. Seasonal variation in leaf, wood and bark concentrations. Environ. Pollut. 2004, 131, 485-494. [CrossRef] [PubMed]

34. Taylor, G.J.; Crowder, A.A. Uptake and accumulation of heavy metals by Typha latifolia in wetlands of the Sudbury, Ontario region. Can. J. Bot. 1983, 61, 63-73. [CrossRef]

35. Odeigah, P.G.C.; Nurudeen, O.; Amund, O.O. Genotoxicity of oil field wastewater in Nigeria. Hereditas 1997, 126, 161-167. [CrossRef]

36. Pichtel, J. Oil and gas production wastewater: Soil contamination and pollution prevention. Appl. Environ. Soil Sci. 2016. [CrossRef]

37. U.S. Environmental Protection Agency (EPA). Drinking Water Contaminants and Standards. Available online: https: / / www.epa.gov / dwstandardsregulations (accessed on 3 April 2018).

38. Ahnstrom, Z.A.S.; Parker, D.R. Cadmium reactivity in metal-contaminated soils using a coupled stable isotope dilution-sequential extraction procedure. Environ. Sci. Technol. 2001, 35, 121-126. [CrossRef] [PubMed]

39. Buekers, J.; Van Laer, L.; Amery, F.; Van Buggenhout, S.; Maes, A.; Smolders, E. Role of soil constituents in fixation of soluble Zn, Cu, Ni and Cd added to soils. Eur. J. Soil Sci. 2007, 58, 1514-1524. [CrossRef]

40. Buekers, J.; Degryse, F.; Maes, A.; Smolders, E. Modelling the effects of ageing on Cd, Zn, Ni and Cu solubility in soils using an assemblage model. Eur. J. Soil Sci. 2008, 59, 1160-1170. [CrossRef]

41. Davis, A.; Ruby, M.V.; Bergstrom, P.D. Factors controlling lead bioavailability in the Butte mining district, Montana, USA. Environ. Geochem. Health 1994, 16, 147-157. [CrossRef] [PubMed] 